\title{
The role of volatile organic compounds in the polluted urban atmosphere of Bristol, England
}

\author{
A. C. Rivett, D. Martin, D. J. Gray, C. S. Price, G. Nickless, P. G. Simmonds, S. J. O’Doherty, B. R. Greally, \\ A. Knights, and D. E. Shallcross \\ Biogeochemistry Research Centre, School of Chemistry, University of Bristol, Cantock's Close, Bristol, BS8 1TS, UK
}

Received: 15 August 2002 - Published in Atmos. Chem. Phys. Discuss.: 13 February 2003

Revised: 24 May 2003 - Accepted: 31 July 2003 - Published: 12 August 2003

\begin{abstract}
The results of a field campaign carried out from early spring through to the late summer of 2000 , in Bristol, England, are presented. Continuous measurements of over 40 hydrocarbons have been made at an urban background site, located at Bristol University, for approximately nine months using a Gas Chromatography - Flame Ionisation Detection (GC-FID) system and for a selection of halocarbons for approximately one month using a Gas Chromatography - Electron Capture Detection (GC-ECD) system. In this paper we present the time-series of the nine halocarbons and selected hydrocarbons. Daytime and night-time hydroxyl radical concentrations have been estimated based on the diurnal variations of a selection of the measured hydrocarbons. The average summer daytime concentration of $\mathrm{OH}$ was found to be $2.5 \times 10^{6}$ molecules $\mathrm{cm}^{-3}$ and the night-time concentration to be in the range $10^{4}$ to $10^{5}$ molecules $\mathrm{cm}^{-3}$. In addition, the role played by certain VOCs in the formation of ozone is assessed using the POCP (Photochemical Ozone Creation Potential) concept.
\end{abstract}

\section{Introduction}

The urban environment contains a complex mixture of chemicals, however, due to the high levels of $\mathrm{NO}_{\mathrm{x}}$ that generally persist, ozone formation is VOC (volatile organic compound) limited (e.g. Sillman, 1999). Therefore, it is of great importance to determine the type of VOC that is present in the urban environment, its concentration and how this varies both spatially and temporally. This study has investigated both local and remote effects on levels of pollutants in the Bristol conurbation. A detailed understanding of the different in-

Correspondence to: A. C. Rivett

(alison.rivett@lineone.net) fluences on local air quality is important to inform relevant policy decisions such as transport planning and healthcare provision and this type of research provides such information.

The behaviour of halocarbons in the stratosphere and the remote troposphere is well understood due to their major role in ozone depletion, yet there have been few studies in urban areas. A handful of investigations have been carried out in Taiwan, Brazil and Japan (Wang et al., 1998; Grosjean et al., 1999; Yamamoto et al., 2000). There are several reasons for the study halocarbons in urban atmospheres. Their degradation products are sources of the $\mathrm{Cl}$ radical which acts like the $\mathrm{OH}$ radical and so may change the oxidising capacity of the troposphere. In addition, the health effects are significant, these compounds are potentially toxic, irritant and carcinogenic. Emissions in Britain are regulated by the UK Environment Agency, but are not systematically monitored.

In urban conurbations, the sources and behaviour of hydrocarbons are generally well identified and understood (Wayne, 2000; UK PORG, 1997; Derwent et al., 2000). Their overwhelming source is rush-hour traffic, inducing a diurnal cycle upon which is added transported air masses bringing polluted or clean air from other regions. In addition to being a measure of air quality, the hydrocarbon measurements can also provide useful information about the chemistry of the polluted atmosphere. For example, the formation of ozone and other photochemical pollutants in the $\mathrm{NO}_{\mathrm{x}}$-rich urban atmosphere is VOC-limited, so it is useful to determine which species are making the greatest contribution to ozone formation. Concentrations of $\mathrm{OH}$ and other radicals can be calculated during the day and night, as can the magnitude of dispersion processes taking place. Simple source identification is also possible using these types of data but this analysis is not discussed here. 


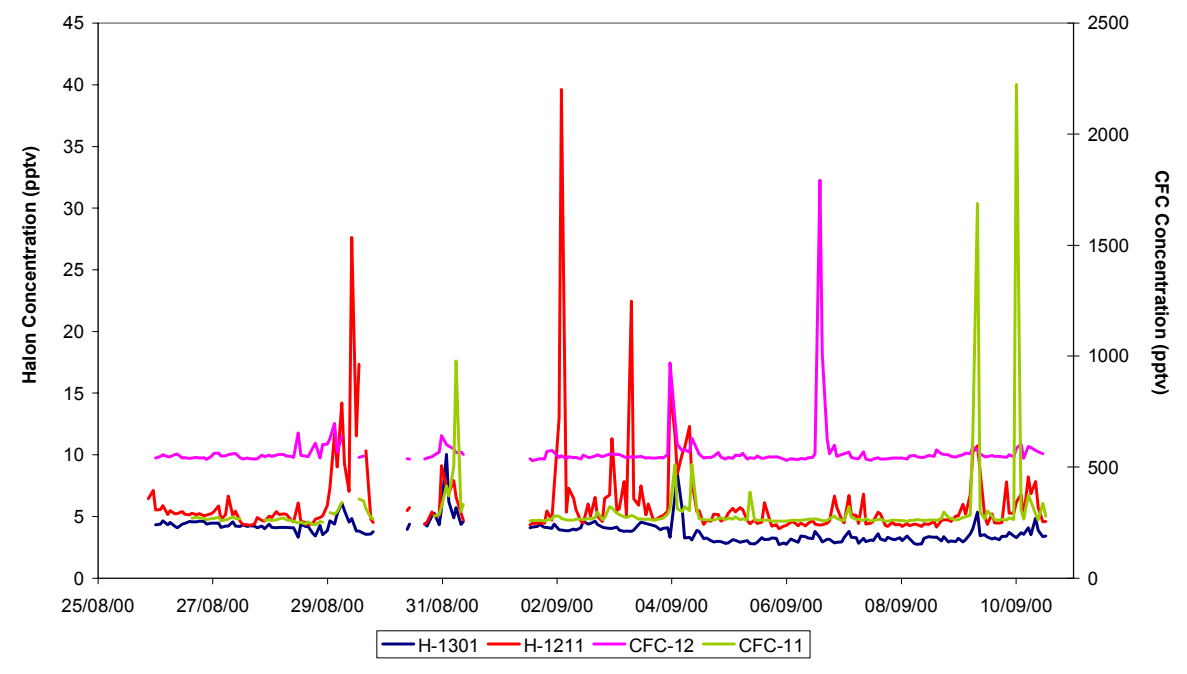

Fig. 1. Time-series of halons and CFCs.

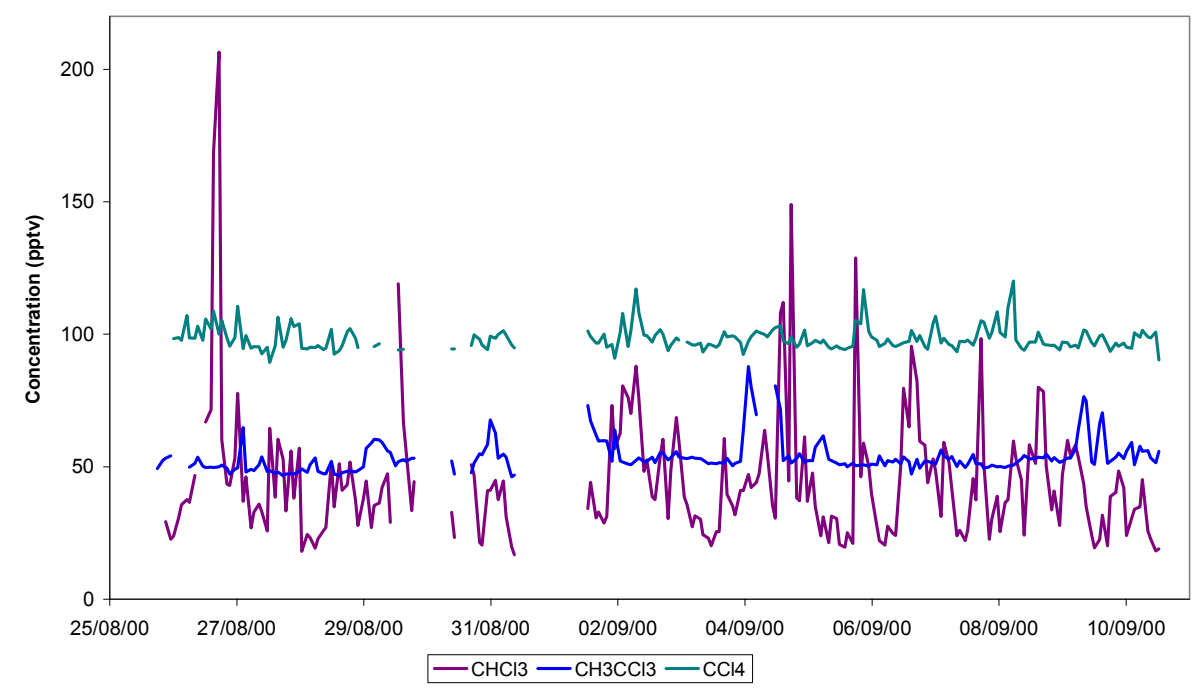

Fig. 2. Time-series of the three chlorinated compounds.

\section{Experimental}

Bristol $\left(51.5^{\circ} \mathrm{N}, 2.75^{\circ} \mathrm{W}\right)$, with a population of almost half a million people, is situated in the south-west of Britain, 120 miles west of London. Like any other town or city, Bristol has its own distinctive atmospheric characteristics. It is located a short way from the coast, and is surrounded by hills. The city centre basin covers an area of approximately 25 square kilometres, although the suburbs extend much further. To the west of the city is a large industrial area (Avonmouth) and other key industries include manufacturing and business. Two major motorways run nearby and the volume of traffic around the area is generally high. The basin geography combined with heavy traffic flow can lead to the build-up of pollutants during anti-cyclonic weather conditions, although prevailing winds are often from the clean, western Atlantic sector.

From early spring to late summer 2000, continuous measurements of VOCs were made at an urban background site, located at the University of Bristol. The Automatic Adsorption-Desorption System (ADS) and GC technology developed at Bristol (Simmonds et al., 1995; Sheppard, 1999; Bassford et al., 1998) was used to perform routine analysis of air and standard samples in a continuous cycle. Over 40 hydrocarbon species were measured using a GCFID system with a Peltier-cooled ADS to achieve low temperature trapping at minus $40^{\circ} \mathrm{C}$. The measurement period was approximately nine months. A GC-ECD was deployed concurrently at the same sampling point to monitor a selection of nine halocarbons for one month using an ADS which 


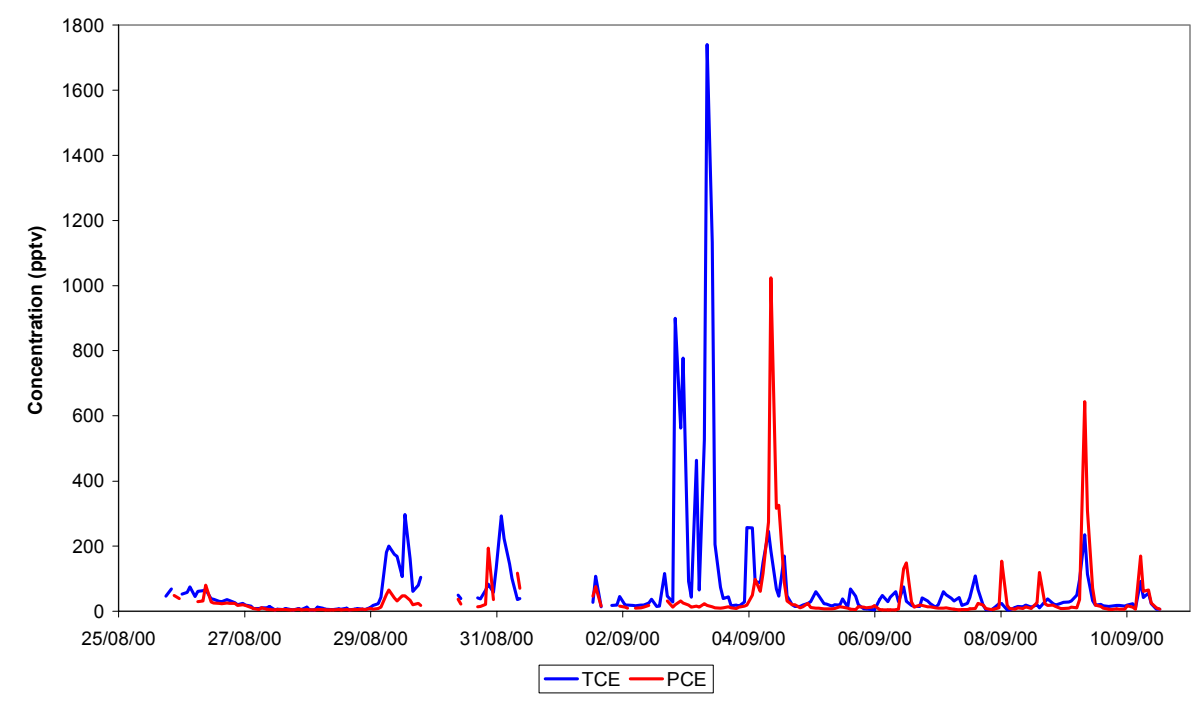

Fig. 3. Time-series of trichloroethene and perchloroethene.

traps at ambient temperature (Bassford et al., 1998). Measurements of a smaller set of hydrocarbons were taken simultaneously at a roadside site in the centre of Bristol, as part of the UK national monitoring network, NETCEN (Derwent et al., 2000). The species monitored by the three systems were; $\mathrm{C}_{2}-\mathrm{C}_{8}$ Hydrocarbons, CFCs 11 and 12, Halons 1211 and $1301, \mathrm{CHCl}_{3}$ (Chloroform), $\mathrm{CH}_{3} \mathrm{CCl}_{3}$ (Methyl Chloroform), $\mathrm{CCl}_{4}$ (Carbon Tetrachloride), TCE (Trichloroethene) and PCE (Perchloroethene).

\section{Halocarbons in the City}

Figures 1 to 3 show the concentrations of the nine halocarbons measured in Bristol between August and September 2000. A complex time-series is observed for the halocarbons, with large variations in the concentrations measured. There are some episodes where several compounds are simultaneously elevated, however there are also periods where just one compound is elevated, in complete contrast to the coherent variations observed for most hydrocarbons, which are driven primarily by vehicular sources. Figure 4 shows the halocarbon time-series overlaid with toluene as a representative hydrocarbon. No weekly or diurnal trends were found for any of the halocarbons, as might be expected for compounds with no significant biogenic or automobile sources. In general, halocarbon levels measured at the urban site are similar to those measured at Mace Head, Ireland, a rural background site which is part of the AGAGE (Advanced Global Atmospheric Gases Experiment) monitoring network (Prinn et al., 2000). The only exceptions are chloroform and methyl chloroform which are significantly elevated above background levels. Results of the halocarbon monitoring campaign and correlations between the halocarbons and hydrocarbons are discussed further in Rivett et al. (2003).

\section{Hydrocarbons in the City}

The summer time-series of a representative selection of the hydrocarbons measured are shown in Fig. 5. The concentration time-series' are very similar for each of the compounds measured. This is consistent with what would be expected as these compounds all have a primarily vehicular source. There are periods of high pollution when many compounds are elevated and "clean" periods where most species are at relatively low levels. In the sections which follow, the hydrocarbon dataset is interrogated to estimate both daytime and night-time $\mathrm{OH}$ levels.

In the analysis of this type of dataset, investigation of the variation in hydrocarbon ratios can be a powerful tool (Calvert, 1976). Calculating the ratios of each of the hydrocarbons to one reference compound enables differences in their sources and reactivity to be elucidated. Using ratios removes day-to-day variations, meteorological factors and differences in emission strengths between the compounds (Roberts et al., 1984; Parrish et al., 1998). In this study, benzene has been used as the reference compound because its lifetime is longest of all the compounds measured (it has the slowest reaction rate with $\mathrm{OH}$ ) and no significant non-traffic sources have been characterised in the UK VOC emission inventory (Derwent et al., 2000). Therefore, as an air mass is chemically processed, the ratios of all the other species to benzene will decrease.

\subsection{Daytime $\mathrm{OH}$}

It is well established that the $\mathrm{OH}$ radical is the main initiator of atmospheric chemistry during the day (Wayne, 2000). The concentration of the hydroxyl radical during the day was estimated from the variation in concentration ratios of four aromatic species (ethyl benzene, toluene, $o$-xylene and 


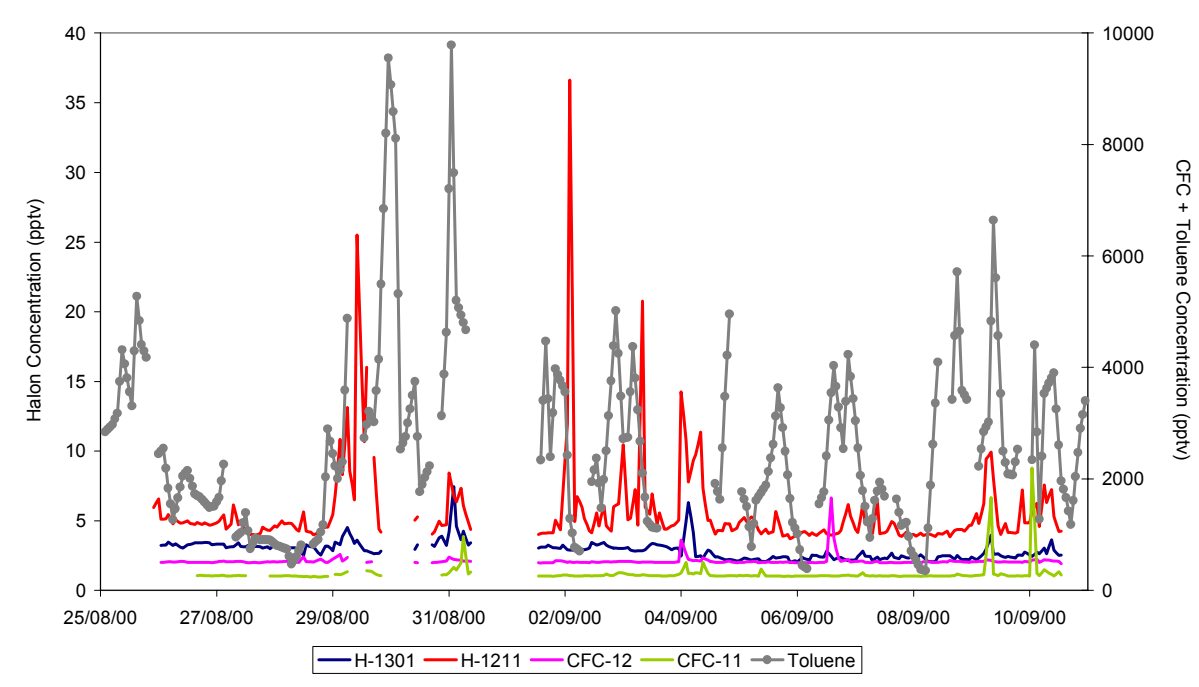

Fig. 4a. Time-series of halons and CFCs overlaid with a representative hydrocarbon, toluene.

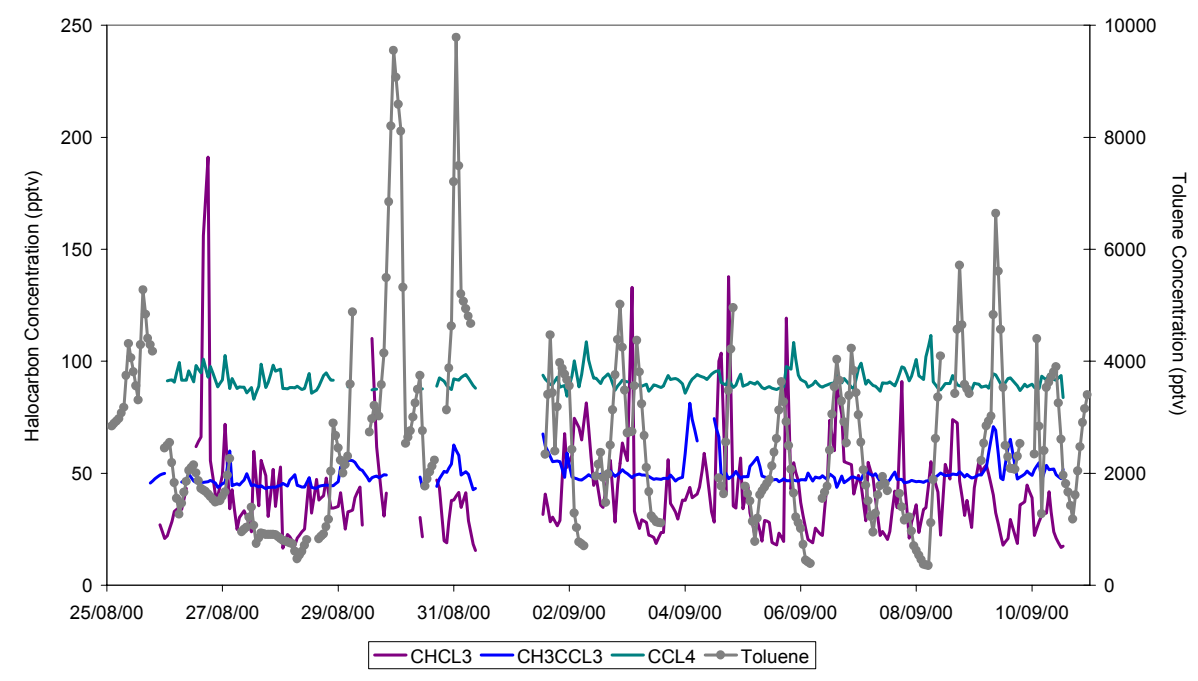

Fig. 4b. Time-series of the 3 chlorinated compounds overlaid with a representative hydrocarbon, toluene.

Table 1. Daytime hydroxyl radical concentrations in Bristol, UK (Summer 2000), estimated from the mean ratios of four aromatic species to benzene

\begin{tabular}{cc}
\hline OH Concentration & $($ molecules cm \\
& -3 \\
\hline Average & $2.5 \times 10^{6}$ \\
Maximum & $8.8 \times 10^{6}$ \\
Minimum & $1.5 \times 10^{5}$ \\
\hline
\end{tabular}

$m+p$-xylene) to benzene (Blake et al., 1993; Moschonas et al., 2001). Aromatics are most suitable for this type of calculation because they have similar lifetimes and sources to benzene and decay almost exclusively by reaction with the hydroxyl radical. From the change in a compounds' ratio to benzene between the morning rush hour period (7:00-10:00) and the midday period (10:00-16:00) the concentration of daytime $\mathrm{OH}$ can be calculated using the following equation, the derivation of which is given in Appendix A:

$[\mathrm{OH}]=\frac{\ln \left(\frac{\frac{X_{t}}{B_{t}}}{\frac{X_{i}}{B_{i}}}\right)}{t\left(K_{B}-K_{X}\right)}$

$X_{i} / B_{i}$ is the ratio of hydrocarbon $X$ to benzene $(B)$ during the morning rush hour, $X_{t} / B_{t}$ is the ratio of hydrocarbon $X$ to benzene $(B)$ over midday, $t$ is the time elapsed between morning rush hour and midday, $K_{B}$ is the rate constant for the reaction of benzene and $\mathrm{OH}$ and $K_{X}$ is the rate constant for the reaction of hydrocarbon $X$ with $\mathrm{OH}$. This gives an 


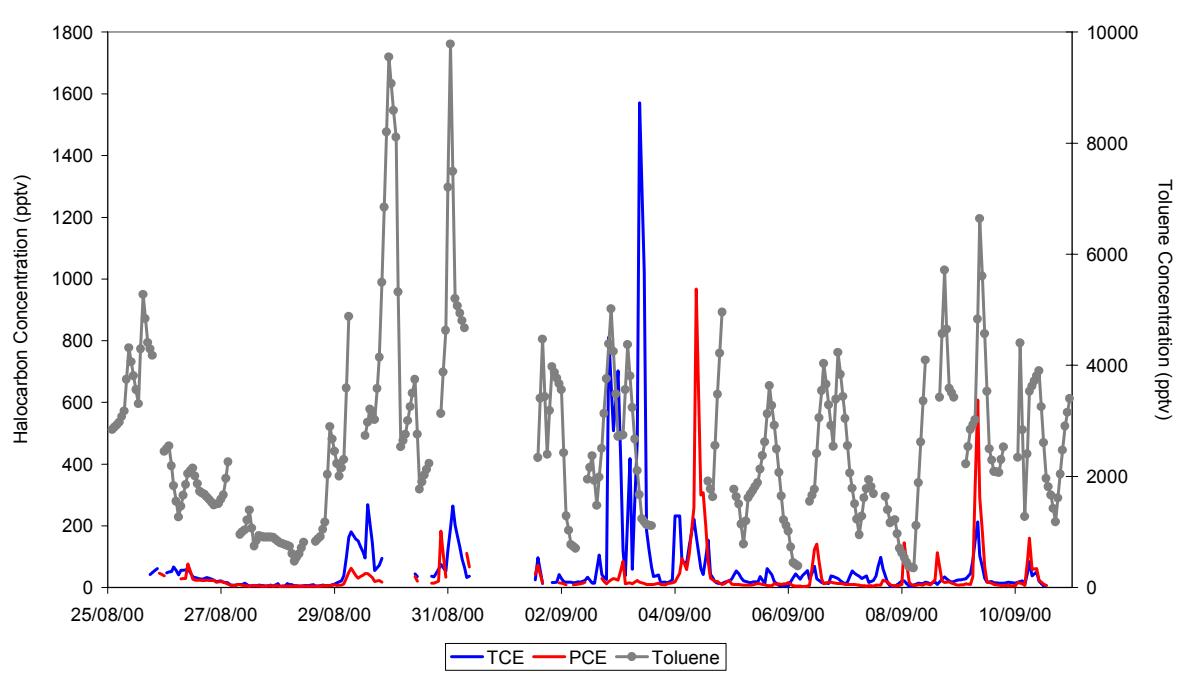

Fig. 4c. Time-series of TCE and PCE overlaid with a representative hydrocarbon, toluene.

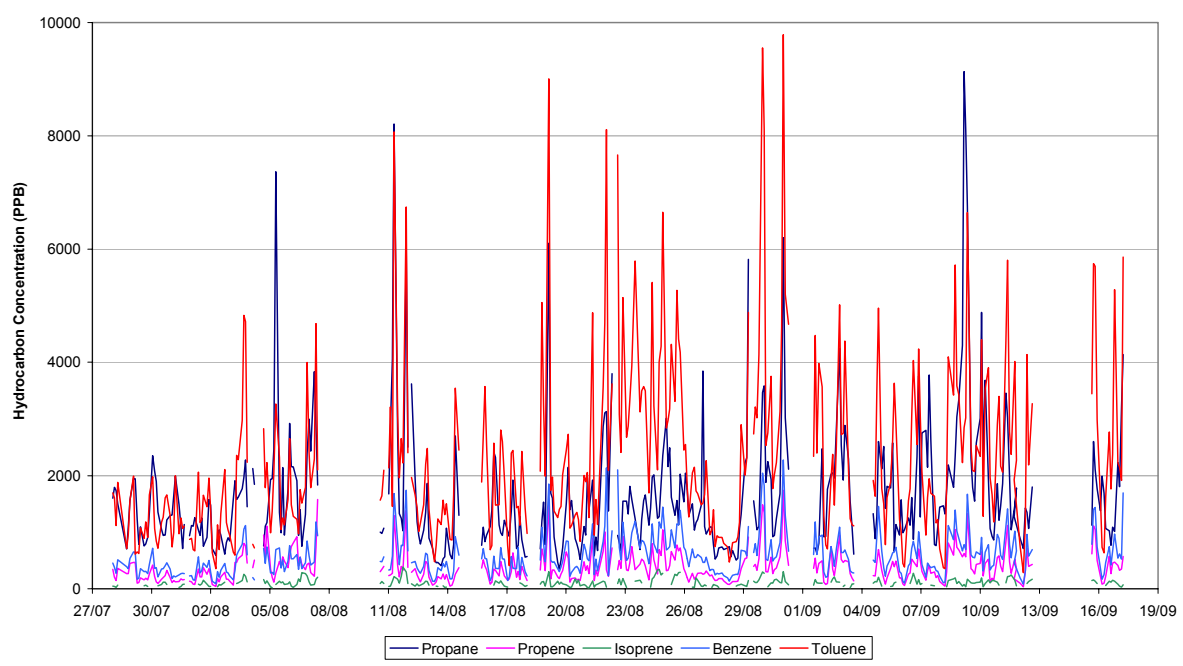

Fig. 5. Hydrocarbon time-series.

average $\mathrm{OH}$ concentration over the time elapsed. The rates of reaction of the VOCs with $\mathrm{OH}$ are given in Table 2.

Ratios to benzene were calculated over the entire campaign to give a typical ratio for each of the four aromatic species during the morning rush hour and midday timeperiods. These ratios were then used to determine an average daytime $\mathrm{OH}$ concentration during the summer. The mean of the four different $\mathrm{OH}$ concentrations calculated from the different aromatic species is given in Table 1 along with the maximum and minimum concentrations calculated.

The average daytime $\mathrm{OH}$ concentration calculated over the course of the campaign was $2 \times 10^{6}$ molecules $\mathrm{cm}^{-3}$. This compares well with what would be expected, as the lifetime of $\mathrm{OH}$ is less than $1 \mathrm{~s}$ and consequently noontime concentrations generally only reach $0.04-0.4 \mathrm{ppt}\left(10^{6}-\right.$ $10^{7}$ molecules $\mathrm{cm}^{-3}$ ) (Wayne, 2000). Field campaigns such as the EASE 1996 and 1997 European background air experiments (Creasey et al., 1997; Creasey et al., 2002) and BERLIOZ (Platt et al., 2002), sampling in the Berlin area, have measured daytime $[\mathrm{OH}]$ of between 1$10 \times 10^{6}$ molecules $\mathrm{cm}^{-3}$ during summer-time.

\subsection{Night-time $\mathrm{OH}$}

Although $\mathrm{NO}_{3}$ is generally thought to be the main oxidising species at night, hydroxyl radicals can be generated even after dark from several reactions (Platt et al., 1990; Mihelcic et al., 1993; Canosa-Mas et al., 1996; Carslaw et al., 1997; Paulson et al., 1997).

$\mathrm{OH}$ can be formed from the reaction of $\mathrm{HO}_{2}$ with the nitrate radical (Eq. 2a), with ozone (Eq. 2b) or with nitric oxide (Eq. 2c): 


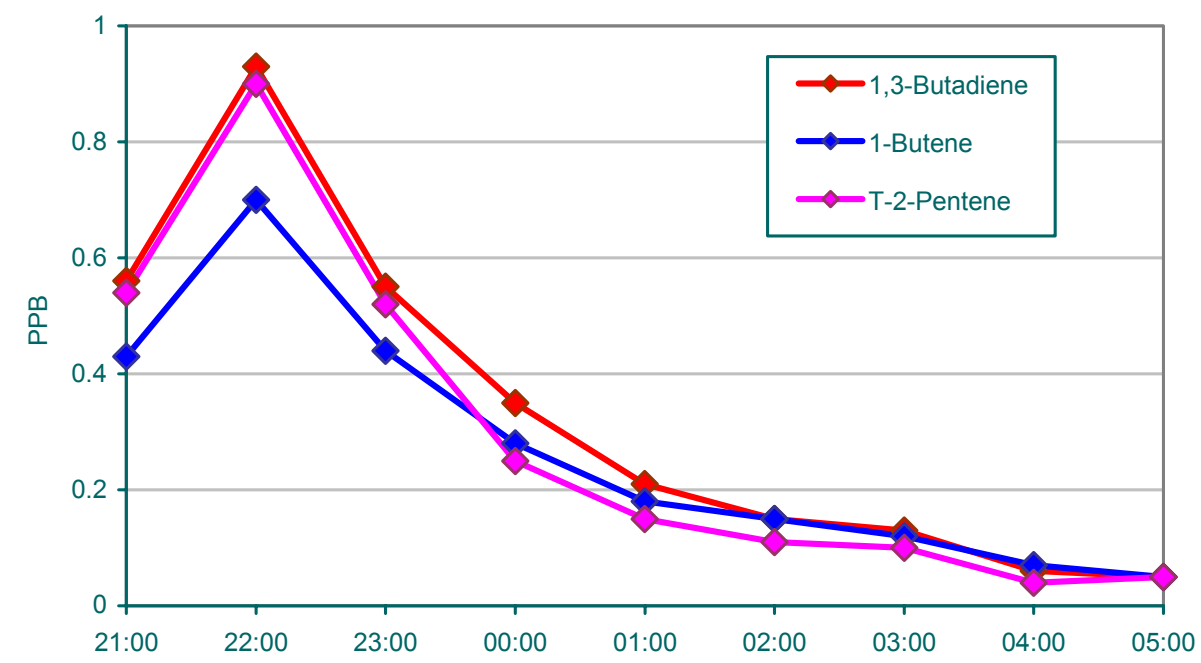

Fig. 6. Representative decay of hydrocarbons on the night of 30-31 August 2000.

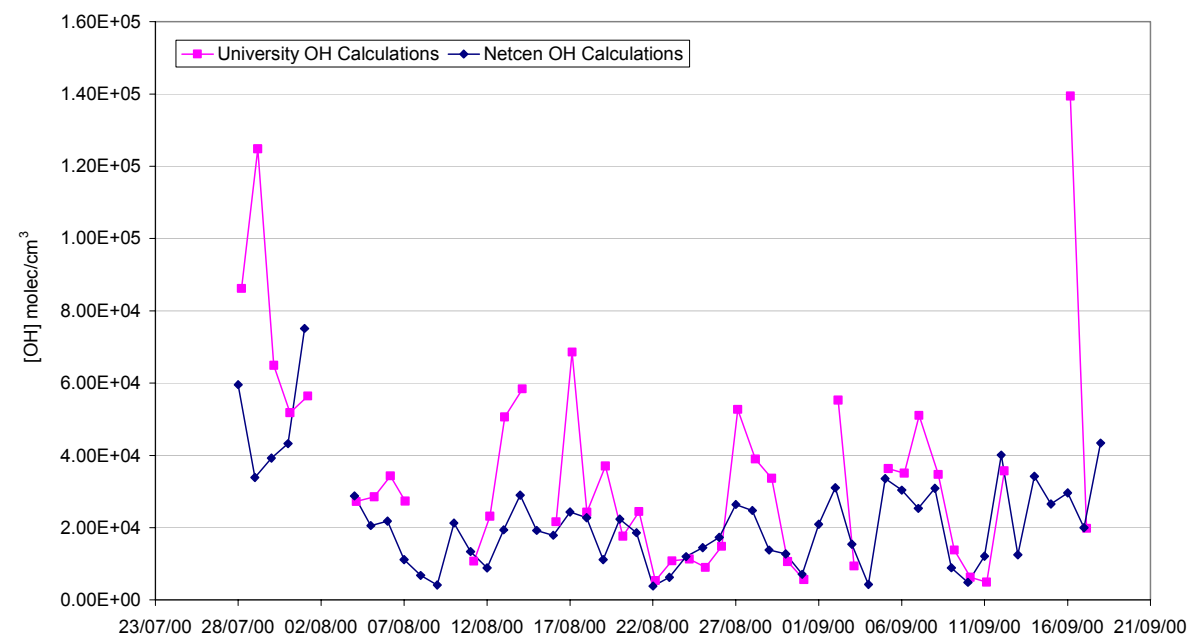

Fig. 7. Steady-state night-time $[\mathrm{OH}]$ calculated for University (urban background) and NETCEN (urban centre) sites.

$$
\begin{aligned}
& \mathrm{HO}_{2}+\mathrm{NO}_{3} \longrightarrow \mathrm{OH}+\mathrm{NO}_{2}+\mathrm{O}_{2} \\
& \mathrm{HO}_{2}+\mathrm{O}_{3} \longrightarrow \mathrm{OH}+2 \mathrm{O}_{2} \\
& \mathrm{HO}_{2}+\mathrm{NO} \longrightarrow \mathrm{OH}+\mathrm{NO}_{2}
\end{aligned}
$$

The reaction of alkenes with the nitrate radical can lead to the formation of $\mathrm{HO}_{2}$, which can be converted to $\mathrm{OH}$ via reactions (2a), (2b) and (2c):

$$
\mathrm{NO}_{3}+\mathrm{CH}_{2}=\mathrm{CH}_{2} \longrightarrow \mathrm{CH}_{2}\left(\mathrm{ONO}_{2}\right) \mathrm{CHO}+\mathrm{HO}_{2}
$$

The ozonolysis of alkenes is a complex reaction, believed to involve the formation of a Criegee intermediate (Eqs. 4 and 5). However, strong evidence exists to suggest that $\mathrm{OH}$ can be formed from these reactions which can proceed all day:

$\mathrm{O}_{3}+\mathrm{CH}_{2}=\mathrm{CH}_{2} \longrightarrow \mathrm{OH}+\mathrm{HCO}$
$\mathrm{HCO}+\mathrm{O}_{2} \longrightarrow \mathrm{CO}+\mathrm{HO}_{2}$

$[\mathrm{OH}]$ can be calculated from an analysis of the decay of VOCs during the night in 2 ways:

\section{Alkene Decays}

Data from nights (such as that shown in Fig. 6) where several alkene species undergo a steady decay due to dispersion and reaction with $\mathrm{OH}, \mathrm{NO}_{3}$ and $\mathrm{O}_{3}$ has been compiled. The rates of reaction of the VOCs and the VOC concentration over the night are known, therefore re-arranging the equation below, radical concentrations can be calculated.

$$
\begin{aligned}
& d[\mathrm{VOC}] / d t= \\
& \quad\left(-k[\mathrm{OH}]-k\left[\mathrm{NO}_{3}\right]-k\left[\mathrm{O}_{3}\right]-k_{\text {dispersion }}\right) \cdot[\mathrm{VOC}]
\end{aligned}
$$


Table 2. Rate constants used in the calculation of daytime and night-time radical concentrations (Atkinson, 1994; Master Chemical Mechanism, 2001)

\begin{tabular}{|c|c|c|c|}
\hline & $\begin{array}{l}\text { Rate of reaction with } \mathrm{OH} \\
\left(\mathrm{cm}^{3} \text { molecules }^{-1} \mathrm{~s}^{-1}\right)\end{array}$ & $\begin{array}{l}\text { Rate of reaction with } \mathrm{O}_{3} \\
\left(\mathrm{~cm}^{3} \text { molecules }{ }^{-1} \mathrm{~s}^{-1}\right)\end{array}$ & $\begin{array}{c}\text { Rate of reaction with } \mathrm{NO}_{3} \\
\left(\mathrm{~cm}^{3} \text { molecules }{ }^{-1} \mathrm{~s}^{-1}\right)\end{array}$ \\
\hline 1,3-Butadiene & $6.66 \times 10^{-11}$ & $6.31 \times 10^{-18}$ & $1.03 \times 10^{-13}$ \\
\hline 1-Butene & $3.14 \times 10^{-11}$ & $9.65 \times 10^{-18}$ & $1.21 \times 10^{-14}$ \\
\hline 2-Methyl Pentane & $5.60 \times 10^{-12}$ & & \\
\hline 3-Methyl Pentane & $5.40 \times 10^{-12}$ & & \\
\hline Benzene & $1.32 \times 10^{-12}$ & & $5.50 \times 10^{-17}$ \\
\hline Ethane & $2.57 \times 10^{-13}$ & & \\
\hline Ethene & $8.64 \times 10^{-12}$ & $1.59 \times 10^{-18}$ & $2.10 \times 10^{-16}$ \\
\hline Ethyl benzene & $7.10 \times 10^{-12}$ & & $5.70 \times 10^{-16}$ \\
\hline Ethyne & $8.15 \times 10^{-13}$ & & \\
\hline i-Butane & $2.33 \times 10^{-12}$ & & \\
\hline i-Pentane & $3.90 \times 10^{-12}$ & & \\
\hline Isoprene & $1.01 \times 10^{-10}$ & $1.28 \times 10^{-17}$ & $6.78 \times 10^{-13}$ \\
\hline $\mathrm{m}+\mathrm{p}$-Xylene & $1.90 \times 10^{-11}$ & & $3.45 \times 10^{-16}$ \\
\hline n-Butane & $2.54 \times 10^{-12}$ & & $6.60 \times 10^{-17}$ \\
\hline n-Hexane & $5.60 \times 10^{-12}$ & & $1.05 \times 10^{-16}$ \\
\hline n-Pentane & $3.96 \times 10^{-12}$ & & $8.10 \times 10^{-17}$ \\
\hline o-Xylene & $1.37 \times 10^{-11}$ & & $3.77 \times 10^{-16}$ \\
\hline Propane & $1.15 \times 10^{-12}$ & & \\
\hline Propene & $2.70 \times 10^{-11}$ & $1.01 \times 10^{-17}$ & $9.40 \times 10^{-15}$ \\
\hline t-2-Butene & $6.40 \times 10^{-11}$ & $1.90 \times 10^{-16}$ & \\
\hline $\mathrm{t}$-2-Pentene & $6.69 \times 10^{-11}$ & $1.60 \times 10^{-16}$ & $3.70 \times 10^{-13}$ \\
\hline Toluene & $5.96 \times 10^{-12}$ & & $6.17 \times 10^{-17}$ \\
\hline
\end{tabular}

A matrix method was used to derive the equations given in Appendix C. Rates of reaction of the alkenes with $\mathrm{OH}, \mathrm{O}_{3}$ and $\mathrm{NO}_{3}$ are given in Table 2. The degradation of alkenes by ozone is ignored, as it is very slow in comparison with the reaction of alkenes with $\mathrm{OH}$ and $\mathrm{NO}_{3}$. Thus, decay data for three different alkenes is required on each night to perform these calculations. During the summer period of the campaign there were seven such nights where sufficient data was collected.

The average night-time $\mathrm{OH}$ concentration was calculated to be $3.8 \times 10^{5}$ molecules $\mathrm{cm}^{-3}$. The estimated $\mathrm{OH}$ concentrations varied over a range of $6.3 \times 10^{4}$ molecules $\mathrm{cm}^{-3}$ to $1 \times 10^{6}$ molecules $\mathrm{cm}^{-3}$. Levels of $\mathrm{NO}_{3}$ calculated by this method range from 2 to $7 \mathrm{ppt}$, with an average from the seven nights being 4.2 ppt. This is consistent with (although somewhat lower than) $\mathrm{NO}_{3}$ concentrations previously measured in urban areas (Platt et al., 2002; Smith et al., 1995). The concentration of $\mathrm{NO}_{3}$ at night is strongly dependent on the levels of alkenes, with which it readily reacts. So in the polluted urban environment, $\mathrm{NO}_{3}$ production could be substantially suppressed. The average rate of dispersion of the alkenes on these seven nights was calculated to be $8 \times 10^{-5} \mathrm{~s}^{-1}$. This gives a transport lifetime $\left(1 / \mathrm{k}_{\text {dispersion }}\right)$ of about three and a half hours, which seems reasonable.

\section{Steady-State Concentration}

The steady-state concentration over one whole night can also be estimated using the following equation:

$$
\begin{aligned}
& d[\mathrm{OH}] / d t=k\left[\mathrm{O}_{3}\right][\text { alkenes }](\text { all summed }) \\
& \quad+k\left[\mathrm{HO}_{2}\right]\left[\mathrm{NO}_{3}\right]+k\left[\mathrm{HO}_{2}\right]\left[\mathrm{O}_{3}\right]+k\left[\mathrm{HO}_{2}\right][\mathrm{NO}] \\
& \quad-k[\mathrm{OH}]\left[\mathrm{NO}_{2}\right][\mathrm{M}]-k[\mathrm{OH}][\mathrm{CO}]-k[\mathrm{OH}][\mathrm{VOC}]
\end{aligned}
$$

Reaction rates of VOCs, $\mathrm{NO}_{2}$ and $\mathrm{CO}$ with $\mathrm{OH}$ and alkenes with ozone are given in Table 2 and Appendix B. The change in $\mathrm{OH}$ is assumed to be equal to the production from the reaction of alkenes with ozone (production from $\mathrm{HO}_{2}$ is ignored, because the concentrations of this radical cannot be known), minus the loss from reactions with $\mathrm{NO}_{2}, \mathrm{CO}$ and other VOCs present.

Figure 7 shows $\mathrm{OH}$ levels calculated for each night of the campaign for the University site and for the city centre site. It can be seen that agreement is generally very good between the two sites. Average $[\mathrm{OH}]$ over the summer campaign period at the University was calculated to be $3.6 \times 10^{4}$ molecules $\mathrm{cm}^{-3}$, ranging from $4.9 \times 10^{3}$ to $1.4 \times 10^{5}$ molecules $\mathrm{cm}^{-3}$. This is a much lower level than that calculated by the decay rate method because only five simple alkene species are used in the calculation and production from $\mathrm{HO}_{2}$ is ignored. If more alkenes were used 
Table 3. $\gamma_{R}$ and $\varepsilon^{\mathrm{POCP}}$ indices, taken from Jenkin, 1998

\begin{tabular}{lcc}
\hline & $\gamma_{R}$ & $\varepsilon^{\mathrm{POCP}}$ \\
\hline 1,3-Butadiene & 4.205 & 109.6 \\
1-Butene & 1.82 & 106.3 \\
2-Methyl Pentane & 0.205 & 48.8 \\
Benzene & 0.061 & 18.7 \\
c-2-Butene & 3.264 & 115.3 \\
c-2-Pentene & 3.028 & 111.4 \\
Ethane & 0.0255 & 12 \\
Ethene & 1 & 97.8 \\
Ethyl benzene & 0.235 & 40.5 \\
Ethyne & 0.113 & 30.8 \\
i-Butane & 0.125 & 34.5 \\
i-Pentane & 0.169 & 37.9 \\
Isoprene & 4.99 & 107 \\
m+p-Xylene & 0.66 & 49.9 \\
n-Butane & 0.136 & 36 \\
n-Heptane & 0.227 & 47.2 \\
n-Hexane & 0.205 & 48.8 \\
n-Pentane & 0.171 & 38.1 \\
o-Xylene & 0.476 & 46 \\
Propane & 0.08 & 29.3 \\
Propene & 2.08 & 113.7 \\
t-2-Butene & 3.704 & 115.3 \\
t-2-Pentene & 3.097 & 111.4 \\
Toluene & 0.23 & 42.1 \\
\hline
\end{tabular}

in the calculation, particularly if heavier and more reactive alkene species were considered, such as isoprene and other monoterpenes, the estimation would be more accurate. Unfortunately, the isoprene data collected was insufficient and monoterpene concentrations were not measured during the campaign. Thus these species cannot be included in the calculations.

Few measurements have been made of $\mathrm{OH}$ at night in similar environments but some comparisons can be made. During the MLOPEX campaign at a remote background site in Hawaii, night-time $[\mathrm{OH}]$ was found to be $1 \times 10^{5}$ molecules $\mathrm{cm}^{-3}$ (Eisele et al., 1996; Cantrell et al., 1997). The PROHET campaign, which took place in a heavily forested area of Michigan measured [OH] as high as $1 \times 10^{6}$ molecules $\mathrm{cm}^{-3}$ after dark (Faloona et al., 2001). A similar campaign in a forest in northern Greece (AEROBIC) also found that $\mathrm{OH}$ in the order of $10^{5}$ molecules $\mathrm{cm}^{-3}$ persisted into the night (Creasey et al., 2001). The BERLIOZ experiment (Platt et al., 2002), measuring in and around the Berlin area, (the area which is probably most similar to the environment studied here) found levels of $1.4 \times 10^{5}$ molecules $\mathrm{cm}^{-3}$. The hydroxyl radical concentrations of $10^{4}$ to $10^{5}$ molecules $\mathrm{cm}^{-3}$ calculated here, even by a relatively simple method, are nevertheless in good agreement with those found in other environments. It is reassuring to note that by using the data derived for $[\mathrm{OH}],\left[\mathrm{NO}_{3}\right]$ and dispersion from the decay method, the calculated decay of measured alkanes is totally consistent.

\subsection{Ozone Creation Potential}

Classifying a wide variety of VOCs in terms of their ability to form ozone is a complex problem, since those compounds which are oxidised quickly lead to significant ozone formation close to the point of emission, whereas those which are oxidised more slowly will lead to ozone being formed further away from the source of the compound, for example in rural areas. Using the concept of Photochemical Ozone Creation Potential (POCP), the role played by each of the hydrocarbons in the creation of ozone has been revealed. In this work $\varepsilon^{\text {POCP }}$ (estimated POCP) values have been used (Jenkin, 1998), which use a mathematical formula (as shown in Eq. 8) to calculate POCP, rather than using a modelling approach:

$\varepsilon^{\mathrm{POCP}}=\alpha_{1} \cdot \gamma_{S} \cdot \gamma_{R}^{\beta}\left(1-\alpha_{2} \cdot \eta_{C}\right)$

$\alpha_{1}, \alpha_{2}$ and $\beta$ are constants, $\eta_{C}$ is the carbon number of the VOC and $\gamma_{S}$ and $\gamma_{R}$ are the structure-based and reactivitybased ozone formation indices respectively. This method replicates well POCPs calculated from the modelling work and also rationalises the POCP values in terms of the intrinsic structural and reactive properties of the VOCs themselves.

$\gamma_{R}$ is a simple approach which defines the relative ozone formation potential of a series of VOCs based on how quickly they form ozone in the boundary layer. $\gamma_{R}$ is based on the rate coefficient $\left(\mathrm{k}_{\mathrm{OH}}\right)$ per reactive bond $\left(\eta_{B}\right)$ (Jenkin, 1998). This is normalised to a value of 1.0 for ethene as shown in Eq. (9):

$\gamma_{R}=\left(k_{\mathrm{OH}} / \eta_{B}\right) \cdot\left(6 / k_{\mathrm{OH}^{\text {ethene }}}\right)$

$\gamma_{R}$ gives a better indication of the impact of VOCs on ozone formation on a local scale, compared to $\varepsilon^{\mathrm{POCP}}$, which gives an indication of the overall regional scale formation. In calculating the contribution to ozone formation all compounds were ratioed to propane. The $\varepsilon^{\mathrm{POCP}}$ and $\gamma_{R}$ indices are given in Table 3.

Plots of the proportion of ozone formed by each class of hydrocarbon as a percentage of the total are shown in Fig. 8. Alkenes produce the greatest amount of ozone (45\% of total) closest to the source of emissions (as calculated using $\gamma_{R}$ ) with aromatic species generating a further $30 \%$. From a large suite of national measurements the UK PORG Report (1997) calculated that alkenes were responsible for $53 \%$ and aromatic species for $28 \%$ of ozone production close to source during summer in the UK. The $\varepsilon^{\mathrm{POCP}}$ values calculated for this campaign show that alkane and aromatic hydrocarbon species have the greatest effect on regional scale ozone production, accounting for approximately $50 \%$ and $30 \%$ respectively. This ties in very well with what would be expected. Close to the point of emission, more reactive compounds such as alkenes will contribute most to ozone formation. As 


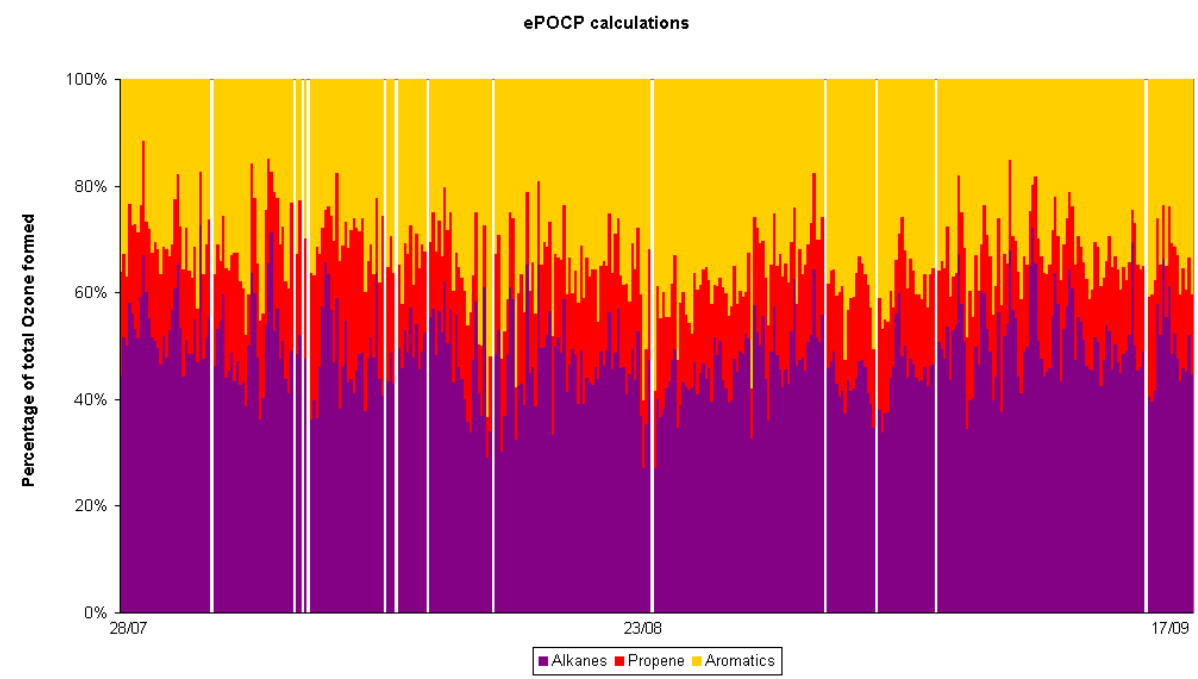

Fig. 8a. Percentage of total ozone formed, calculated by $\varepsilon^{\mathrm{POCP}}$ method.

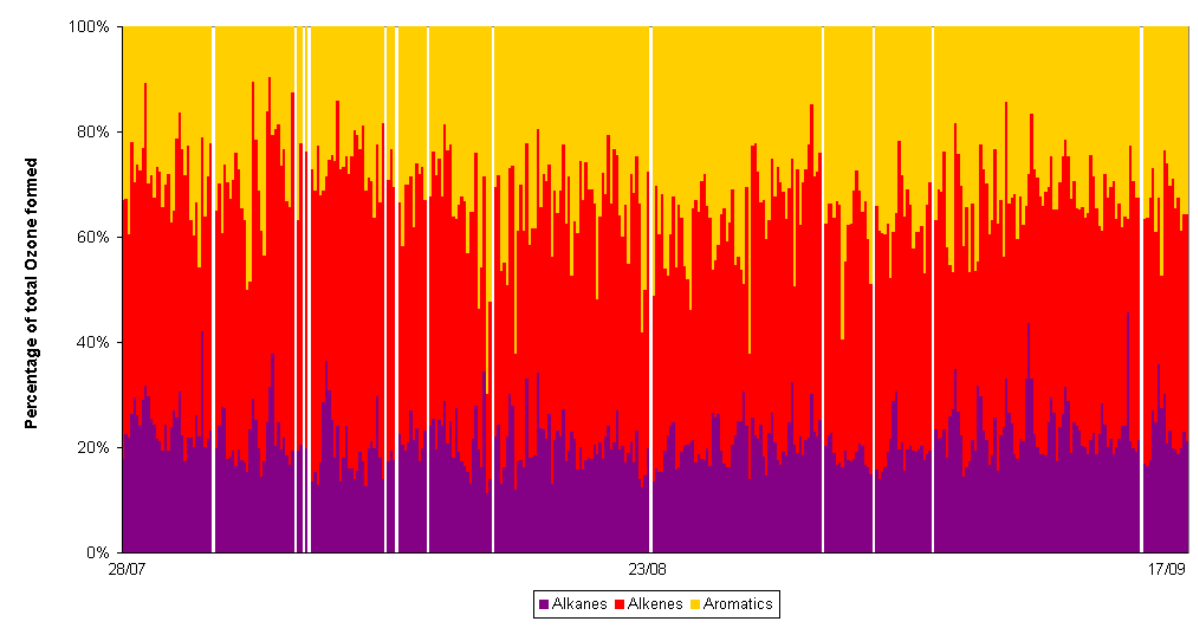

Fig. 8b. Percentage of total ozone formed, calculated by $\gamma_{R}$ method.

time goes on, slower reacting compounds such as the alkanes will become more important in producing ozone.

\section{Conclusions}

Simultaneous measurements of nine different halocarbon species and over forty hydrocarbon species have been made during summer 2000 at an urban background site in a large British city. This unusual dataset has provided a unique opportunity to compare two classes of compounds which display very different behaviour in the urban atmosphere.

The lifetimes of the hydrocarbons measured are all in the order of days, whereas those of the halocarbons measured vary much more considerably from a few days to over a hundred years. Similarly the halocarbons originate from a much more diverse range of sources than do the hydrocarbons studied. Whereas the $\mathrm{C}_{2}-\mathrm{C}_{8}$ hydrocarbons measured at this typical urban site are overwhelmingly emitted by traffic, the halocarbons are emitted from a wide variety of industrial activity, both big factories and smaller businesses, from landfill and other waste processing activity and from the natural environment. Such diversity in lifetime and sources will naturally mean that the behaviour of hydrocarbons compared to halocarbons is very different but it also means that the various halocarbon compounds will not behave in a similar way to each other either. Consequently the time-series of the nine halocarbons are not simple to interpret, they do not display any significant diurnal cycle and each compound has shown large excursions from baseline levels at different points during the campaign. 
A detailed analysis of the hydrocarbon dataset has been made possible by the large number of species measured during this campaign. Radical concentrations have been calculated for both day and night and the estimated $\mathrm{OH}$ concentrations compare well with field measurements made in similar environments. The contribution of different types of hydrocarbons to the formation of ozone in the city centre and further afield has also been quantified.

This type of investigation is an example of how such datasets can be a powerful tool to explore the chemistry and behaviour of urban environments. At this time, when there are numerous schemes to reduce different types of emissions in cities and towns across the world, analyses such as this can have a valuable part to play in informing the decision-making process.

\section{Appendix A}

Derivation of equation used to calculate daytime $\mathrm{OH}$ concentrations. $X_{i}$ and $B_{i}$ are the concentrations of of hydrocarbon $X$ and benzene $(B)$ at the morning rush hour and $X_{t}$ and $B_{t}$ are the concentrations at midday. $t$ is the time elapsed between morning rush hour and midday, $k_{B}$ is the rate constant for the reaction of benzene and $\mathrm{OH}$ and $k_{X}$ is the rate constant for the reaction of hydrocarbon $X$ with $\mathrm{OH}$.

Concentration of compound $X$ at midday: $X_{t}=$ $X_{i} \cdot e^{-k_{x}[\mathrm{OH}] t}$

Concentration of benzene at midday: $B_{t}=B_{i} \cdot e^{-k_{B}[\mathrm{OH}] t}$

$\frac{X_{t}}{B_{t}}=\frac{X_{i} \cdot e^{-k_{X}[\mathrm{OH}] t}}{B_{i} \cdot e^{-k_{B}[\mathrm{OH}] t}}$

$\frac{X_{t}}{B_{t}}=\frac{X_{i}}{B_{i}} e^{\left(-k_{X}[\mathrm{OH}] t-\left(-k_{B}[\mathrm{OH}] t\right)\right)}$

$\frac{\frac{X_{t}}{B_{t}}}{\frac{X_{i}}{B_{i}}}=e^{\left(t \cdot[\mathrm{OH}] \cdot\left(-k_{X}+k_{B}\right)\right)}$

$\ln \frac{\frac{X_{t}}{B_{t}}}{\frac{X_{i}}{B_{i}}}=t \cdot[\mathrm{OH}] \cdot\left(k_{B}-k_{X}\right)$

$[\mathrm{OH}]=\frac{\ln \left(\frac{\frac{X_{t}}{B_{t}}}{\frac{X_{i}}{B_{i}}}\right)}{t\left(k_{B}-k_{X}\right)}$

\section{Appendix B}

Additional rate constants used in the calculation of nighttime $[\mathrm{OH}]$ using a steady-state approximation. Rates of reaction with $\mathrm{OH}$ :

CO: $2.08 \times 10^{-13} \mathrm{~cm}^{3}$ molecules ${ }^{-1} \mathrm{~s}^{-1}$ (Master Chemical Mechanism, 2001)
$\mathrm{NO}_{2}: 1.43 \times 10^{-11} \mathrm{~cm}^{3}$ molecules ${ }^{-1} \mathrm{~s}^{-1}$ (See below for calculation)

The rate of reaction of $\mathrm{NO}_{2}$ and $\mathrm{OH}$ is effectively second order under normal atmospheric conditions and is calculated using the Troe expression:

$k_{t}=\left(\frac{k_{0}[M]}{1+k_{0}[M] / k_{\infty}}\right) F^{\left(1+\left[\log _{10}\left(k_{0}[M] / k_{\infty}\right)\right]^{2}\right)^{-1}}$

where $k_{0}$ and $k_{\infty}$ are the limiting low and high-pressure rate constants respectively, both incorporating a $(T / 300)^{-n}$ temperature dependence and $[M]$ is the atmospheric density. The values used in this calculation were (Master Chemical Mechanism, 2001):

$$
\begin{aligned}
& k_{0}=2.6 \times 10^{-30} \mathrm{~cm}^{6} \text { molecules }{ }^{-2} \mathrm{~s}^{-1} \\
& k_{\infty}=7.7 \times 10^{-11} \mathrm{~cm}^{6} \text { molecules }^{-2} \mathrm{~s}^{-1} \\
& {[M]=2.5 \times 10^{19} \text { molecules } \mathrm{cm}^{-3}} \\
& \mathrm{~F}=0.41
\end{aligned}
$$

$k_{t}$ was calculated to be $1.43 \times 10^{-11} \mathrm{~cm}^{3}$ molecules ${ }^{-1} \mathrm{~s}^{-1}$.

\section{Appendix C}

These equations were derived using a matrix method and used to calculate $\mathrm{OH}, \mathrm{NO} 3$ and dispersion at night from the decay of alkenes.

$$
\begin{aligned}
& {[\mathrm{OH}]=\frac{1}{d e t} \cdot\left(\text { Slope }^{\mathrm{VOCl}}\left(k_{\mathrm{NO}_{3}}^{\mathrm{VOC} 2}-k_{\mathrm{NO}_{3}}^{\mathrm{VOC} 3}\right)+\right.} \\
& \text { Slope } e^{\mathrm{VOC} 2}\left(k_{\mathrm{NO}_{3}}^{\mathrm{VOC} 3}-k_{\mathrm{NO}_{3}}^{\mathrm{VOCl}}\right)+ \\
& \text { Slope } \left.e^{\mathrm{VOC} 3}\left(k_{\mathrm{NO}_{3}}^{\mathrm{VOCl}}-k_{\mathrm{NO}_{3}}^{\mathrm{VOC} 2}\right)\right) \\
& {\left[\mathrm{NO}_{3}\right]=\frac{1}{d e t} \cdot\left(\text { Slope }^{\mathrm{VOCl}}\left(k_{\mathrm{OH}}^{\mathrm{VOC} 3}-k_{\mathrm{OH}}^{\mathrm{VOC} 2}\right)+\right.} \\
& \text { Slope } e^{\mathrm{VOC} 2}\left(k_{\mathrm{OH}}^{\mathrm{VOCl}}-k_{\mathrm{OH}}^{\mathrm{VOC} 3}\right)+ \\
& \text { Slope } \left.e^{\mathrm{VOC} 3}\left(k_{\mathrm{OH}}^{\mathrm{VOC} 2}-k_{\mathrm{OH}}^{\mathrm{VOCl}}\right)\right) \\
& K_{\text {dispersion }}= \\
& \frac{1}{d e t} \cdot\left(S_{\text {sope }} e^{\mathrm{VOCl}}\left(k_{\mathrm{OH}}^{\mathrm{VOC} 2} \cdot k_{\mathrm{NO}_{3}}^{\mathrm{VOC} 3}-k_{\mathrm{NO}_{3}}^{\mathrm{VOC} 2} \cdot k_{\mathrm{OH}}^{\mathrm{VOC} 3}\right)+\right. \\
& \text { Slope } e^{\mathrm{VOC} 2}\left(k_{\mathrm{NO}_{3}}^{\mathrm{VOCl}} \cdot k_{\mathrm{OH}}^{\mathrm{VOC} 3}-k_{\mathrm{OH}}^{\mathrm{VOCl}} \cdot k_{\mathrm{NO}_{3}}^{\mathrm{VOC} 3}\right)+ \\
& \text { Slope } \left.e^{\mathrm{VOC} 3}\left(k_{\mathrm{OH}}^{\mathrm{VOCl}} \cdot k_{\mathrm{NO}_{3}}^{\mathrm{VOC} 2}-k_{\mathrm{NO}_{3}}^{\mathrm{VOCl}} \cdot k_{\mathrm{OH}}^{\mathrm{VOC} 2}\right)\right) \\
& \text { det }=k_{\mathrm{OH}}^{\mathrm{VOCl}}\left(k_{\mathrm{NO}_{3}}^{\mathrm{VOC} 2}-k_{\mathrm{NO}_{3}}^{\mathrm{VOC} 3}\right)-k_{\mathrm{NO}_{3}}^{\mathrm{VOCl}}\left(k_{\mathrm{OH}}^{\mathrm{VOC} 2}-k_{\mathrm{OH}}^{\mathrm{VOC} 3}\right)+ \\
& \left(k_{\mathrm{OH}}^{\mathrm{VOC} 2} \cdot k_{\mathrm{NO}_{3}}^{\mathrm{VOC} 3}-k_{\mathrm{NO}_{3}}^{\mathrm{VOC} 2} \cdot k_{\mathrm{OH}}^{\mathrm{VOC} 3}\right)
\end{aligned}
$$

Acknowledgements. A. C. Rivett, D. J. Gray and C. S. Price would like to thank NERC for studentships and D. Martin thanks Bristol University for a scholarship. We also thank Alan Knights for technical assistance during the campaign. 


\section{References}

Atkinson, R.: Gas-phase tropospheric chemistry of organic compounds, J. Phys. Chem. Ref. Data, Monograph No. 2, 1994.

Bassford, M., Simmonds, P. G., and Nickless, G.: An automated system for near-real-time monitoring of trace atmospheric halocarbons, Anal. Chem., 70, 958-965, 1998.

Blake, N. J., Penkett, S. A., Clemitshaw, K. C., Anwyl, P., Lightman, P., Marsh, A. R. W., and Butcher, G.: Estimates of atmospheric hydroxyl radical concentrations from the observed decay of many reactive hydrocarbons in well-defined urban plumes, J. Geophys. Res., 98, 2851-2864, 1993.

Calvert, J. G.: Hydrocarbon involvement in photochemical smog formation in Los Angeles atmosphere, Environ. Sci. Technol., 10, 256-262, 1976.

Canosa-Mas, C. E., King, M. D., Lopez, R., Percival, C. J., Wayne, R. P., Shallcross, D. E., Pyle, J. A., and Daele, V. J.: Is the reaction between $\mathrm{CH}_{3} \mathrm{C}(\mathrm{O}) \mathrm{O}_{2}$ and $\mathrm{NO}_{3}$ important in the nighttime troposphere? J. Chem. Soc. Faraday Trans., 92, 2211-2222, 1996.

Cantrell, C. A., Shetter, R. E., Calvert, J. G., Eisele, F. L., and Tanner, D. J.: Some considerations of the origin of nighttime peroxy radicals observed in MLOPEX 2, J. Geophys. Res., 102, 15 89915913, 1997.

Carslaw, N., Carpenter, L. J., Plane, J. M. C., Allan, B. J., Burgess, R. A., Clemitshaw, K. C., Coe, H., and Penkett, S. A.: Simultaneous observations of nitrate and peroxy radicals in the marine boundary layer, J. Geophys. Res., 102, 18 917-18 933, 1997.

Creasey, D. J., Heard, D. E., and Lee J. D.: Eastern Atlantic Spring Experiment 1997 (EASE97) 1. Measurements of OH and HO2 concentrations at Mace Head, Ireland, J. Geophys. Res., 107, 10.1029/2001JD001568, 2002.

Creasey, D. J., Halford-Maw, P. A., Heard, D. E., Pilling, M. J., and Whitaker, B. J.: Implementation and initial deployment of a field instrument for measurement of $\mathrm{OH}$ and in the troposphere by laser-induced $\mathrm{HO}_{2}$ fluorescence, J. Chem. Soc., Faraday Trans., 93, 2907-2913, 1997.

Creasey, D. J., Heard, D. E., and Lee, J. D.: $\mathrm{OH}$ and $\mathrm{HO}_{2}$ measurements in a forested region of north-western Greece, Atmos. Environ., 35, 4713-4724, 2001.

Derwent, R. G., Davies, T. J., Delaney, M., Dollard, G. K., and Field, R. A.: Analysis and interpretation of the continuous hourly monitoring data for $26 \mathrm{C}_{2}-\mathrm{C}_{8}$ hydrocarbons at 12 United Kingdom sites during 1996, Atmos. Environ., 34, 297-312, 2000.

Eisele, F. L., Tanner, D. J., Cantrell, C. A., and Calvert, J. G.: Measurements and steady-state calculations of $\mathrm{OH}$ concentrations at Mauna Loa Observatory, J. Geophys. Res., 101, 14 665-14 679, 1996.

Faloona, I., Tan, D., Brune, W., Hurst, J., and Barket Jr., D.: Nighttime observations of anaomalously high levels of hydroxyl radicals above a deciduous forest canopy, J. Geophys. Res., 106, 24 315-24 333, 2001.

Grosjean, E., Rasmussen, R. A., and Grosjean, D.: Toxic air contaminants in Porto Alegre, Brazil. Environ. Sci. Technol., 33, 1970-1978, 1999.

Jenkin, M. E.: Photochemical Ozone and PAN Creation Potentials: Rationalisation and Methods of Estimation. AEAT Report 4182/20150/003, Issue 1, National Environmental Technology Centre, UK, 1998.
Master Chemical Mechanism: The Master Chemical Mechanism website, chmlin9.leeds.ac.uk/MCMframe.html, 2001.

Mihelcic, D., Klemp, D., Musgen, P., Patz, H. W., and VolzThomas, A.: Simultaneous measurements of peroxy and nitrate radicals at Schauinsland, J. Atmos. Chem., 16, 4, 313-335, 1993.

Moschonas, N., Glavas, S., and Kouimtzis, T.: $\mathrm{C}_{3}$ to $\mathrm{C}_{9}$ hydrocarbon measurements in the two largest cities of Greece, Athens and Thessaloniki, Calculation of hydrocarbon emissions by species, Derivation of hydroxyl radical concentrations, Sci. Total Environ., 271, 117-133, 2001.

Parrish, D. D., Trainer, M., Young, V., Goldan, P. D., Kuster, W. C., Jobson, B. T., Fehsenfeld, F. C., Lonneman, W. A., Zika, R. D., Farmer, C. T., Riemer, D. D., and Rodgers, M. O.: Internal consistency tests for evaluation of measurements of anthropogenic hydrocarbons in the tropsphere, J. Geophys. Res., 103, 22339 $22359,1998$.

Paulson, S. E., Sen, A. D., Liu, P., Fenske, J. D., and Fox, M. J.: Evidence for formation of $\mathrm{OH}$ radicals from the reaction of $\mathrm{O}_{3}$ with alkenes in the gas phase, Geophys. Res. Lett., 24, 31933196, 1997.

Platt, U., Alicke, B., Dubois, R., Geyer, A., Hofzumahaus, A., Holland F., Martinez, M., Mihelcic, D., Klüpfer, T., Lohrmann, B., Pätz, W., Perner, D., Rohrer, F., Schäfer, J., and Stutz, J.: Free radicals and fast photochemistry during BERLIOZ, J. Atmos. Chem., 42, 359-394, 2002.

Platt, U., LeBras, G., Poulet, G., Burrows, J. P., and Moortgat, G.: Peroxy radicals from nighttime reaction of NO3 with organic compounds, Nature, 348, 147-149, 1990.

Prinn, R. G., Weiss, R. F., Fraser, P. J., Simmonds, P. G., Cunnold, D. M., Alyea, F. N., O’Doherty, S., Salameh, P., Miller, B. R., Huang, J., Wang, R. H. J., Hartley, D. E., Harth, C., Steele, L. P., Sturrock, G., Midgley, P. M., and McCulloch, A.: A history of chemically and radiatively important gases in air deduced from ALE/GAGE/AGAGE, J. Geophys. Res., 105, 17 751-17 792, 2000.

Rivett, A. C., Martin, D., Nickless, G., Simmonds, P. G., O’Doherty, S. J., Gray, D. J., and Shallcross, D. E.: In-situ gas chromatographic measurements of halocarbons in an urban environment, Atmos. Environ., 37, 2221-2235, 2003.

Roberts, J. M., Fehsenfeld, F. C., Liu, S. C., Bollinger, M. J., Hahn, C., Albritton, D. L., and Sievers, R. E.: Measurements of aromatic hydrocarbon ratios and NOx concentrations in the rural troposphere: Observations of air mass photochemical ageing and NOx removal, Atmos. Environ., 18, 2421-2432, 1984.

Sheppard, V.: The near real time monitoring of NMHCs in tropospheric air. Thesis (Ph.D.), University of Bristol, 1999.

Sillman, S.: The relation between ozone, NOx and hydrocarbons in urban and polluted rural environments, Atmos. Environ., 33, 1821-1845, 1999.

Simmonds, P. G., O’Doherty, S. J., Nickless, G., Sturrock, G. A., Swaby, R., Knight, P., Ricketts, J., Woffendin, G., and Smith, R.: Automated gas-chromatograph mass-spectrometer for routine atmospheric measurements of the CFC replacement compounds, the hydrofluorocarbons and hydrochlorofluorocarbons, Anal. Chem., 67, 717-723, 1995.

Smith, N., Plane, J. M. C., Nien, C. F., and Solomon, P. A.: Nighttime radical chemistry in the San Joaquin valley, Atmos. Environ., 29, 2887-2897, 1995. 
UK PORG: Ozone in the United Kingdom. United Kingdom Photochemical Oxidants Review Group Report, Department of the Environment, London, 1997.

Wang, J. L., Chang, C. J., and Lin, Y. H.: Concentration distributions of anthropogenic halocarbons over a metropolitan area, Chemosphere, 36, 2391-2400, 1998.
Wayne, R. P.: Chemistry of Atmospheres (3rd Ed.). Oxford University Press, Oxford, 2000.

Yamamoto, N., Okayasu, H., Murayama, S., Mori, S., and Hunahashi, K.: Measurement of volatile organic compounds in the urban atmosphere of Yokohama, Japan, by an automated gas chromatographic system, Atmos. Environ., 34, 4441-4446, 2000. 